Celebes Abdimas: Jurnal Pengabdian Kepada Masyarakat

http://journal.lldikti9.id/CER/index

Vol 2, No, 1, April 2020, pp 26-31

p-ISSN:2656-7938 dan e-ISSN: 2657-1870

DOI: https://doi.org/10.37541/celebesabdimas.v2i1.259

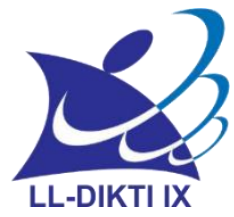

\title{
Penerapan Teknologi Aplikasi SIPTA Guna Mendukung PKW Minapolitan Swasembada Pangan Ikan di Kabupaten Konawe Utara
}

\author{
Fajriah', Kobajashi Togo Isamu' ${ }^{2}$, Ahmad Mustafa ${ }^{3}$, Hasnia Arami ${ }^{4}$ \\ ${ }_{1}^{1}$ Pemanfaatan Sumberdaya Perikanan, Universitas Muhammadiyah Kendari, Indonesia \\ 2Teknologi Hasil Perikanan Perikanan, Universitas Haluoleo, Indonesia \\ 3,4Manajemen Sumberdaya Perairan, Universitas Haluoleo, Indonesia \\ 1Email : rhia.fajriah@gmail.com
}

\section{Artikel info}

Article history:

Received: November-2019

Revised: Januari-2020

Accepted: April-2020

Publish: April-2020
Abstract. The application of Capture Fisheries Information System (SIPTA) technology application aims to provide information on the distribution of fish in the waters around Konawe Utara Regency to fishermen and all interested parties, while also providing information on the average catch production and its types, also providing price information. to consumers. So that it can indirectly increase theincome of fishermen. Theimplementation methoduse is through training and discussion with fishermen, located in Molawe Village, Konawe Utara District from June to July 2019. Based on the results of the implementation of this activity, it was concluded that this application was especially needed by training participants in Molawe Village and the community in general, those who need information about capture fisheries in Konawe Village. The analysis used is in the form of quantitative or data collection as a basis for information originating from fishermen. As for the results of their activities, the fishing community in Molawe Village has had a SIPTA application that contains capture fisheries data and information.

Abstrak. Penerapan teknologi Aplikasi Sistem Informasi Perikanan Tangkap (SIPTA) bertujuan untuk memberikan informasi Daerah penyebaran ikan di perairan sekitaran Kabupaten Konawe Utara kepada nelayan dan semua pihak yang berkepentingan, selain itu sekaligus memberikan informasi data rata-rata produksi hasil tangkapan beserta jenisnya, juga memberikan informasi harga kepada konsumen. Sehingga dengan demikian secara tidak langsung dapat meningkatkan pendapatan nelayan. Metode pelaksanaan yang digunakan yaitu melalui pelatihan dan diskusi dengan nelayan, berlokasi di Kelurahan Molawe, Kabupaten Konawe Utara pada bulan Juni sampai dengan Juli 2019. Berdasarkan hasil pelaksanaan kegiatan ini diperoleh kesimpulan bahwa aplikasi ini sangatlah diperlukan khususnya oleh nelayan peserta Pelatihan di Kelurahan Molawe dan masyarakat luas pada umumnya yang membutuhkan informasi tentang perikanan tangkap di Kelurahan Konawe. Analisis yang digunakan berupa kuantitatif atau pengumpulan data-data sebagai dasar informasi 


\begin{tabular}{|c|c|}
\hline & $\begin{array}{l}\text { yang berasal dari nelayan. Adapun hasil kegiatannya saat ini } \\
\text { masyarakat nelayan di Kelurahan Molawe telah memiliki aplikasi } \\
\text { SIPTA yang berisi data dan informasi perikanan tangkap. }\end{array}$ \\
\hline Keywords: & Coresponden author: \\
\hline Teknologi; & Fajriah \\
\hline Aplikasi Sistem & Pemanfaatan Sumberdaya Perikanan, Universitas Muhammadiyah \\
\hline Informasi: & Kendari, Indonesia \\
\hline Perikanan Tangkap; & Email:rhia.fajriah@gmail.com \\
\hline (SIPTA); penyebaran & (c) $\underset{\mathrm{BY}}{\text { (i) }}$ \\
\hline ikan; perairan & artikel dengan akses terbuka dibawah lisensi CC BY -4.0 \\
\hline
\end{tabular}

\section{PENDAHULUAN}

Kabupaten Konawe Utara tepatnya di Kelurahan Molawe merupakan salah satu daerah yang terpilih dan dijadikan sebagai kawasan minapolitan sektor perikanan di Provinsi Sulawesi Tenggara. Dimana kawasan ini dibangun dan dikembangkan dengan konsep yang dititik beratkan pada kemajuan sektor perikanan dengan mengedepankan prinsip efisiensi, kualitas, percepatan dan berkesinambungan. Sejalan dengan tujuan pembangunan minapolitan untuk menumbuhkan serta meningkatkan kemandirian ekonomi kecil dan skala mikro, menambah kualitas ekonomi menengah ke atas untuk memiliki daya saing yang tinggi dalam pasar global, dan menjadikan sektor ekonomi kelautan dan perikanan sebagai penggerak ekonomi regional, menjadi dasar pelaksanaan Program Kemitraan Wilayah (PKW) di Kabupaten Konawe Utara. Sektor perikanan di kabupaten utara hingga saat ini masih menjadi salah satu sektor utama disamping sektor perkebunan. Hal ini didukung oleh kondisi alam yang terhubung langsung dengan Laut Banda. Aktifitas warga di Kelurahan Molawe sangat erat dengan sektor perikanan tangkap. Bahkan sebagian besar penduduk bermatapencaharian sebagai nelayan. Namun seperti pada kondisi masyarakat nelayan di pelosok pada umumnya sering sekali terkendala dengan masalah informasi perikanan tangkap, baik dari informasi akses area penangkapan ikan yang layak, informasi jumlah produksi dan jenis ikan hasil tangkapan, dan yang paling penting adalah informasi mengenai harga ikan. Padahal informasi ini sangatlah penting karena akan sangat membantu aktivitas perikanan tangkap nelayan pada umumnya. Hal ini sesuai dengan yang diungkapkan oleh Haluan J, dkk (2012) bahwa kekayaan potensi perikanan Indonesia memerlukan penanganan tersendiri sehingga dapat dimanfaakan secara optimal salah satunya adalah melalui sistem informasi manajemen dalam perikanan tangkap. Sistem informasi manajemen dalam perikanan tangkap merupakan hal yang sangat dibutuhkan terutama dalam pengelolaan perikanan.

Saat ini masyarakat dapat dikatakan tidak bisa lagi menghindari atau menutup diri dari suatu sistem informasi. Hal ini seiring dengan tuntutan perkembangan zaman yang semakin luas dan maju ditambah jumlah permintaan konsumen yang semakin meningkat terkadang tidak seimbang dengan hasil tangkapan yang tersedia dan teridentifikasi. Informasi ketersediaan ikan disuatu daerah dapat dijadikan acuan untuk mengetahui seberapa besar potensi sumberdaya perikanan didaerah tersebut. Selain itu dapat pula dijadikan dasar untuk meningkatkan produksi dan peningkatan efektifitas distribusi ikan, sebagaimana yang diungkapkan oleh Arthatiani FY, dkk (2018) tentang pola konsumsi dan model permintaan ikan, dan sesuai pula dengan hasil penelitian Virgantani F, dkk (2011) tentang permintaan produk ikan oleh penduduk di Indonesia.

Penerapan dan pengembangan sistem informasi perikanan tangkap pada program Kemitraan ini didasari pula oleh Undang-undang Republik Indonesia Nomor 45 tahun 2009 tentang perubahan atas Undang-undang Nomor 31 Tahun 2004 tentang Perikanan pasal 46 ayat 2 yang menyatakan bahwa pemerintah dan pemerintah daerah perlu mengadakan pusat data dan informasi dan data statistik perikanan. Berdasarkan penetapan undangundang ini, maka dapat dikatakan bahwa pengembangan sistem informasi perikanan termasuk 
dalam hal pengelolaan sumberdaya dan lingkungan perikanan tangkap adalah bagian penting dari kegiatan pembangunan perikanan di Indonesia (Mustaruddin, 2012). Hal ini didukung pula oleh Kompas (2010) yang menyatakan bahwa pembangunan perikanan hanya akan berhasil baik bila didukung oleh data dan informasi relevan yang memudahkan pengambilan keputusan pengembangan secara cepat, tindakan implementasi yang tepat, dan menetapkan upaya control terhadap aktivitas pembangunan perikanan. membantu

Penataan data dan informasi perikanan tangkap secara tepat akan sangat

pemerintah dan masyarakat dalam mengelola potensi sumberdaya alamnya. Hingga saat ini data tentang sumberdaya dan lingkungan perikanan tangkap baik tingkat provinsi maupun kabupaten belum terdata secara rinci dan masih tersebar pada beberapa instansi terkait yang juga memiliki program terkait lingkungan dan perairan. Dunia internet atau dunia maya saai ini telah menjadi kebutuhan primer bagi semua orang utamanya bagi para pekerja atau pelajar karena akan mempermudah seluruh pekerjaan dan mempersingkat waktu (Masruri, 2013).

Oleh karena itu melihat betapa pentingnya informasi dan data yang akurat, mudah untuk diakses dan terbaru untuk pemanfaatan sumberdaya perikanan tangkap di Kabupaten Konawe Utara tepatnya di Kecamatan Molawe dibutuhkan suatu sistem informasi dengan menggunakan teknologi aplikasi SIPTA. Teknologi aplikasi SIPTA merupakan aplikasi informasi sumberdaya perikanan tangkap berbasis Web, sehingga dapat diakses dengan mudah dengan memanfaatkan sistem internet melaui android maupun perangkat komputer. Dimana program ini adalah program unggulan pada kegiatan pengabdian masyarakat Program Kemitraan Wilayah (PKW).

Terdapat definisi informasi yang dijadilkan landasan teori pada kegiatan ini, dimana menurut Laudon dan Laudon (1998), informasi adalah daya yang telah diolah menjadi bentuk yang bermakna dan berguna bagi manusia. (Pilone D, 2005). Sedangkan Aplikasi adalah komponen yang berfungsi untuk melakukan pengolahan data maupun kegiatankegiatan berupa dokumen ataupun untuk keperluan pengolahan data (Kusnadi dkk, 2017).

\section{Metode}

Pengabdian yang dilakukan oleh kolaborasi antara dosen perguruan tinggi yakni dari Fakultas Perikanan dan Ilmu Kelautan Universitas Muhammadiyah Kendari dengan Fakultas Perikanan dan Ilmu Kelautan Universitas Halu Oleo ini adalah pengabdian Program Kemitraan Wilayah (PKW). Lokasi program PKW terletak di Kelurahan Molawe, Kabupaten Konawe Utara, Provinsi Sulawesi Tenggara. Masyarakat atau kelompok Mitra yang dipilih tentunya adalah masyarakat yang berhubungan dan merasakan langsung dengan hadirnya program PKW ini, yakni masyarakat yang profesi utamanya adalah sebagai nelayan dan memiliki alat tangkap sendiri yang tergolong dalam usaha perikanan skala kecil. Di harapkan agar para penggiat usaha perikanan skala kecil di Kelurahan Molawe dapat menikmati dan memanfaatkan informasi perikanan tangkap diwilayah mereka secara online.

Kegiatan pengabdian kepada masyarakat ini bertujuan agar nelayan di Kelurahan Molawe mampu memanfaatkan media internet secara efektif, sehingga dapat menggairahkan dan meningkatkan produktivitas usaha perikanan tangkap yang selama ini nelayan dianggap sebagai kelompok masyarakat yang termarginalkan. Pelaksanaan kegiatan pengabdian masayarakat PKW dengan program sosialisasi dan penerapan aplikasi teknologi SIPTA dilaksanakan di Kelurahan Molawe pada bulan Juni sampai Juli 2019 dengan beberapa tahapan kegiatan antara lain :

1) Diawali dengan survey lapangan untyuk memastikan kondisi terkini Kelurahan Molawe

yang meliputi kondisi sumberdaya alamnya dan kondisi sumber daya manusianya dan juga infrastruktur yang dapat dijadikan tolak ukur layak tidaknya program ini dilaksanakan di Kelurahan Molawe, Kabupaten Kobawe Utara. 
29| Celebes Abdimas: Jurnal Pengabdian Kepada Masyarakat

2) Mengkoordinasikan kegiatan ini dengan pemerintah setempat dalam hal ini Lurah Molawe dan pihak kantor Badan Perencanaan Daerah (Bapeda) Kabupaten Konawe Utara yang menjadi mitra pendukung program PKW secara umum.

3) Mendata dan menentapkan 30 orang calon Molawe peserta pelatihan melalui bantuan lurah dan ketua kelompok nelayan sekaligus ketua RW di kelurahan Molawe.

4) Melaksanakan kegiatan sosialisasi dan pelatihan yang dipusatkan di Aula Kantor Lurah Molawe, Kabupaten Konawe Utara.

5) Pelaksanaan kegiatan terdiri dari sosialisasi atau pengenalan terhadap Alikasi SIPTA kepada masyarakat nelayan Kelurahan Molawe.

6) Kegiatan kedua adalah pelatihan penggunaan aplikasi SIPTA sekaligus diskusi dengan kelompok- kelompok nelayan yang menjadi mitra dalam kegiatan program PKW.

7) Mengumpulkan data-data nelayan, data produksi jumlah hasil tangkapan dan jumlahnya

, data harga dan juga data daerah peyebaran ikan yang selanjutnya data-data ini akan dimasukan dalam aplikasi SIPTA sehingga memberikan data yang baik dan benar untuk selanjutnya di masukan dalam "playstore".

8) Mengambil titik-titik daerah penangkapan dengan bantuan GPS yang diketahui sebagai area penyebaran ikan. Data-data ini juga selanjutnya memjadi bagian dari data pada aplikasi SIPTA.

9) Memonitoring penggunaan aplikasi dan meng-up date informasi dan data dari nelayan Kelurahan Molawe pada aplikasi SIPTA.

\section{Hasil Dan Pembahasan}

Kegiatan pengabdian kepada masyarakat ini terdiri dari tim pengabdi utama yang terdiri dari 4 orang, dibantu oleh 5 orang tim lapangan, dan 1 orang operator. Kegiatan ini melibatkan masyarakat nelayan di Kelurahan Molawe Kabupaten Konawe Utara, terdiri dari 3 tahap pelaksanaan, yakni 1) Tahap Sosialisasi, 2) Tahap Pelatihan, 3) Tahap Monitoring.

1) Tahap Sosialisasi :

Tahap awal ini adalah berupa pengenalan tentang aplikasi SIPTA, dalam hal ini pemateri memberi pemahaman tentang arti pentingnya sistem informasi untuk saat ini dan masa yang akan datang demi keberlanjutan usaha dan kegiatan perikanan tangkap di Kabupaten Konawe. Teknologi digital, pengunaan internet dan segala sesuatu yang berkaitan dengan hal tersebut adalah sesuatu yang harus diterima bahkan dinikmati bukan untuk dihindari karena kondisi zaman yang menuntut hal tersebut.

2) Tahap Pelatihan

Pada tahap kedua ini lebih bersifat teknis tentang bagaimana menggunakan aplikasi ini pada HP Android. Mulai dari cara mengakses atau mendownload, membuka dan membaca informasi yang ada didalamnya. Analisis Tolls yang terdapat didalamnya adalah UML (Unified Modeling Language) adalah bahasa spesifikasi standar yang digunakan untuk mendokumentasikan, menspesifikasikan dan membangun perangkat lunak (Cholones, 2003). Mcleod R, (2013) Juga menambahkan bahwa UML merupakan metodologi dalam mengembangakan sistem berorientasi objek dan juga merupakan alat untuk mendukung pengembangan sistem.

3) Tahap Monitoring dan Evaluasi

Tahap ini lebih banyak dilakukan oleh operator SIPTA UMK, karena semua aktifitas penggunaan lebih banyak terekam pada aplikasi ini, sselain itu tim juga secara langsung kelapangan melihat langsung penggunaan SIPTA dan implikasinya terhadap nelayan di Kelurahan Molawe, Kabupaten Konawe Utara. 
Sasaran penggunaan aplikasi ini selain masyarakat nelayan juga adalah pemerintah setempat, masyarakat umum yang berkepentingan dengan bidang perikanan. Aplikasi ini dibuat sesederhana mungkin agar dapat dimanfaatkan oleh semua pihak. Dimana tujuan utama yang melatarbelakangi pembuatan aplikasi ini adalah agar informasi-informasi penting seputar perikanan tangkap dapat terdata secara detail, akurat dan aktual (sesuai dengan kondisi sekarang dilapangan).

Sinergitas antar perguruan tinggi (Universitas Muhammadiyah Kendari dan Universitas Haluoleo) dengan pemerintah Kabupaten Konawe Utara (Bapeda dan Kelurahan Molawe) serta mitra pengguna (kelompok nelayan Molawe) melalui pogram pengabdian kepada masyarakat Program Kemitraan Wilayah (PKW) pada kegiatan ini adalah salah satu bukti implementasi bidang ilmu, sumberdaya, pengaloksian dana yang digunakan untuk kepentingan peningkatan taraf hidup masayarakat nelayan, dan untuk pengelolaan lingkungan dan sumberdaya perikanan yang berkelanjutan. Keberadaan aplikasi ini diharapkan dapat meningkatkan produktifitas nelayan dan juga sebagai sarana promosi daerah sebagai sentra perikanan tangkap.
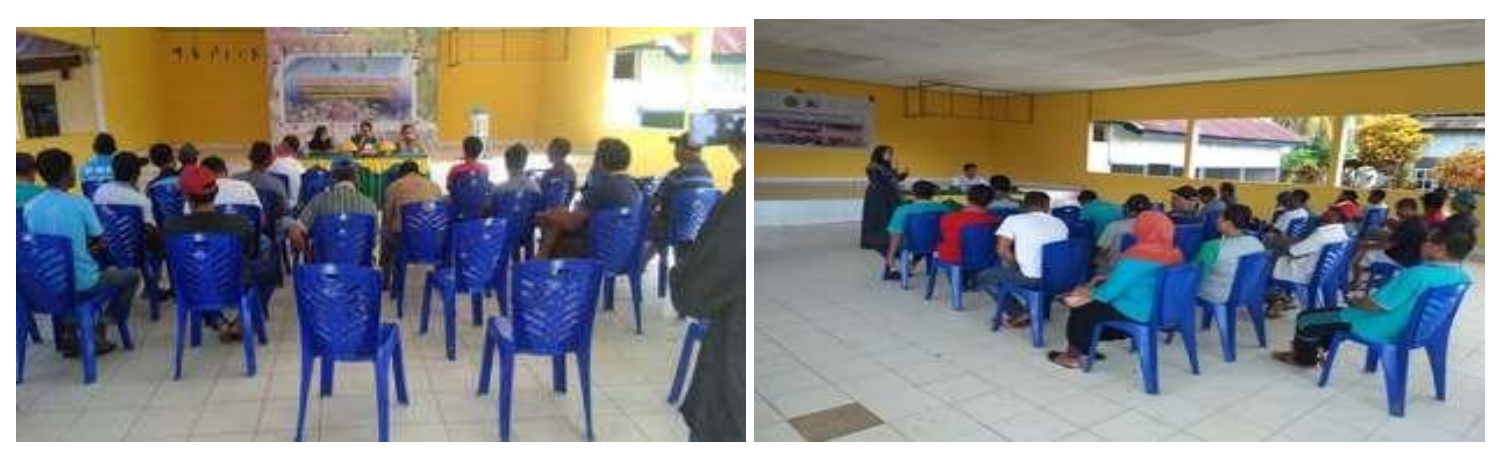

Gambar 1. Tahap Sosialisasi Penerapan Aplikasi SIPTA ke Masyarakat di Kelurahan Molawe dan Gambar 2. Kegiatan Pelatihan Aplikasi SIPTA ke Kelompok-kelompok Nelayan Kelurahan Molawe

\section{Simpulan Dan Saran}

Berdasarkan pembahasan diatas maka simpulan yang dapat diperoleh dan digambarkan mengenai kegiatan program ini secara keseluruhan bahwa kegiatan pengenalan dan pelatihan aplikasi Sistem Informasi Perikanan Tangkap (SIPTA) bisa diterima oleh seluruh masayrakat nelayan dan juga pemerintah di Kelurahan Molawe Kabupaten Konawe Utara. Mereka telah menyadari seutuhnya bahwa betapa pentingnya sistem infomasi bagi kemajuan dan keberlanjutan usaha perikanan tangkap yang menjadi masa depan anak-anak mereka. Ditambahlagi walaupun masih sederhana namun aplikasi SIPTA sekaligus dapat dijadikan sarana untuk mempromosikan hasil tangkapan nelayan di Kelurahan Molawe pada masyarakat dunia yang lebih luas.

Adapun saran pada kegiatan ini antara lain : (1) dibutuhkan keseriusan pemerintah untuk mendukung usaha perikanan tangkap skala kecil yang masih banyak terdapat kendala, (2) Program ini diharapkan terus berlanjut melalui dukungan pemerintah setempat minimal hingga terlihat hasil nyata bagi nelyan, (3) Pengembangan dari aplikasi SIPTA terus dilakukan agar kedepannya dapat digunakan sebagai sarana pemasaran on line oleh setiap nelayan di Kabupaten Konawe Utara. 
31| Celebes Abdimas: Jurnal Pengabdian Kepada Masyarakat

\section{Daftar Rujukan}

Arthatiani, Dkk. 2108. Analisis Pola Konsumsi Dan Model Permintaan Ikan Menurut Karakteristik Rumah Tangga Di Indonesia. Jurnal Sosial Ekonomi Perikanan. Vol.13. No.1 Tahun 2018. E-ISSN : 2527-4805

Cholones. 2003. Unified Modeling Language (UML). 2012. Willey Publishing Inc. USA.

Haluan J. dkk. 2012. Pengembangan Sisrtem Informasi Manajemen Perikanan Tangkap Dalam rangka Pengembangan Industrialisasi Perikanan Laut. Journal of Marine Fisheries. Vol.3, No.2 November 2012. ISSN. 2087-4235.

Hidayat R, dkk. 2016. Desain Sistem Informasi Perikanan Pole and Line Berbasis Online di Perairan Teluk Bone. Jurnal Ipteks PSP, Vol.3 No.6, Oktober 2016, ISSN : 484-500.

Kompas. 2010. Mengembangkan Sistem Informasi Kelautan dan Perikanan. Harian Kompas. Jakarta. Indonesia.

Kusnadi dkk. 2017. Aplikasi Informasi Hasil Penangkapan Ikan Berbasis Web (Studi kasus: Pelabuhan Perikanan Nusantara Kejawaan DKP3 Kota Cirebon. Jurnal Digit, Vol.7, No.1 Mei 2017, ISSN : 2088-589X

Mcleod, Raymond. 2013. Pengertian dean Fungsi Sistem Informasi, Jakarta : PT. Prenhallindo. Pilone, D. dan Pitman, Neil. 2005. UML. 2.0 in Nutshell. California; O’Reilly Media

Undang-undang Republik Indonesia Nomor 45 tahun 2009. Tentang Perubahan Atas Undang undang Nomor 31 Tahun 2004 tentang Perikanan.

Virgantari F, Dkk. 2011. Analisis Permintaan Ikan Di Indonesia: Pendekatan Model Quadratic Almost Ideal Demand System (Quaids). Jurnal Sosial Ekonomi Perikanan. Vol. 6 No.2 Tahun 2011. E-ISSN : 2527-4805. 